\title{
DIFFERENT MEASURES OF VULNERABILITY IN THEIR RELATION TO DIFFERENT DIMENSIONS OF FEAR OF CRIME
}

\begin{abstract}
Martin Killias and Christian Clerici*
Vulnerability has, in research conducted over the last decade, been found to be significantly related to fear of crime. It seems to be particularly helpful in explaining seemingly disproportionate fear levels among women and the elderly, as well as in a few situational contexts. In the present research, a representative sample of Switzerland's population $(N=726)$ was interviewed on various aspects of fear of crime in the public sphere. All respondents were asked how they assessed their own ability to escape or resist in case of an attack by a young assailant. In addition, interviewers rated several aspects of respondents' 'visible'vulnerability. In multivariate analyses, vulnerability, as assessed by respondents themselves, explained fears and worries about crime better than interviewer-assessed measures of vulnerability. It is concluded that, in comparison to demographic and contextual (neighbourhood) variables, physical vulnerability seems to play an important and consistent role in the genesis of fear of crime.
\end{abstract}

Over many years, fear of crime was seen as a function of media exposure, or as a consequence of neighbourhood characteristics and-direct or indirect-exposure to crime. Drawing on the work by Skogan and Maxfield (1981), who first introduced vulnerability as a theoretical concept in this context, as well as on research on fear in different (e.g. military) contexts, the first author presented a theoretical model focusing on vulnerability as a key concept in the genesis of fear of crime (Killias 1990, 1991). This model distinguishes between, on one hand, personal, social and situational aspects of vulnerability, such as gender or age, living in certain areas, and neighbourhood characteristics (Vrij and Winkel 1991), and, on the other hand, several dimensions of threats, i.e. the probability of crime, the seriousness of feared consequences ('how bad will it be') and the feeling of having no control (Bandura 1986; Goffman 1973) over the likelihood of (criminal) events, nor their outcome (seriousness). This model uses nine cells of different combinations between the several dimensions of vulnerability and fear of crime. Since it has been able to integrate much research data on fear of crime in the streets, it has been discussed and somewhat enlarged in theoretical (Hale 1996; Alimam 1993; Schwarzenegger 1991), as well as in empirical research. Of particular interest in this context are:

- the British Crime Survey of 1994 and 1998, where physical size, health condition and confidence in self-defence abilities were found to be correlated with worries about violent crime (Hough 1995, 1996; Mirrlees-Black and Allen 1998); almost identical

\footnotetext{
* School of Forensic Science and Criminology, University of Lausanne, Switzerland. The authors would like to thank Corinne Brignoli, student of forensic science at University of Lausanne, for help with updating this paper's documentation. They also appreciate the valuable suggestions by two anonymous reviewers who encouraged them to amplify certain methodological aspects.
} 
questions were asked during the 1987 Swiss Crime Survey, with very similar results (Killias 1989: 162);

- the German Survey on Victimization and Fear of Crime in 1993, where indirect measures of vulnerability turned out to be more correlated with fear of crime than age (Greve et al. 1996: 77-82);

- the work by Fisher and Nasar $(1992,1995)$ on situational aspects of vulnerability, i.e. certain characteristics of the physical (spatial) environment ('hotspots of fear') which increase objective vulnerability (perceived exposure and loss of control) and, thus, fear.

The empirical relevance of the model remains relatively open, especially for the validity of empirical measures of personal, social and situational vulnerability; there also remains the question in what sense vulnerability relates to risk assessment (Walklate 1997). Usually, besides the examples mentioned above, personal vulnerability continues to be measured by sex and age, as it was in Skogan and Maxfield (1981). Even if alternative measures of vulnerability are used, it remains open how valid subjective indicators of (perceived) vulnerability are, as opposed to objective measures such as, for example, physical handicaps.

The present research tries to test empirically the validity of a variety of objective and subjective measures of personal vulnerability, and to see their impact on fear of crime in six different situational contexts. Since the data reported here were not collected during a crime survey, the dimension of victimization and its impact on fear of crime cannot be assessed. However, earlier research has shown fear to be, at best, moderately and inconsistently associated with victimization in cross-sectional research (Hough 1996; Schwarzenegger 1991; Killias 1989). Since the focus of this paper is on the relevance and validity of different measures of vulnerability in relation to several dimensions of fear of crime, the lack of data on victimization among respondents should not affect the conclusions too much.

Survey Methodology

\section{Sample}

The present survey was undertaken to test several indicators of fear and vulnerability. The long-term goal was to select a few valid measures to be used in surveys designed to monitor public opinion on crime, fear of crime and attitudes to punishment over the next ten years. ${ }^{1}$ For that purpose, a sample of 726 Swiss nationals was personally interviewed during November 1997; they were selected according to a combined random-quota sampling method which has been developed and standardized over several years. Selection variables were town of residence ${ }^{2}$ (randomly selected), gender, age and professional status (selected by the interviewer according to quotas). ${ }^{3}$ This

\footnotetext{
${ }^{1}$ These repeated (annual) surveys will be conducted by the Gesellschaft für Sozialforschung. We thank the GfS staff and particularly Dr Vera Herrmann and Alex Martinovits for careful execution of the field work and valuable help in analysing potential interviewer effects

${ }^{2}$ No interviews take place in the interviewer's area of residence.

${ }^{3}$ No interviewer conducted more than 20 interviews.
} 
method produces results of perfectly acceptable reliability, especially if, as here, correlations are in the centre of interest. The sample is representative for the Swiss population aged 18 to 84 in the German as well as in the French-speaking parts of the country. ${ }^{4}$

\section{Interviews}

The interviewers did not get special training for this particular survey, since they belong to a staff dealing with similar surveys several times per year. Most interviews took place at the respondent's home. ${ }^{5}$ The ratings (e.g. of the respondent's vulnerability) were, in most cases, added by the interviewer shortly after the interview had been completed. They did not know, however, the hypotheses behind the interview questions and ratings. More than 10 per cent of the interviews have been controlled by the survey institute.

Interviewer assessments of respondent characteristics could not be subjected to tests of interrated reliability. Special attention will, therefore, be given to potential effects of interviewer characteristics on responses given during the interview, and on interviewer ratings of respondent and area characteristics.

\section{Measures of Fear of Crime}

The respondents were asked, among other things, several questions concerning fear of crime in different contexts. ${ }^{6}$ Three questions ask how the respondent feels, ${ }^{7}$ i.e. safe or unsafe, after 10 p.m., while

(a) walking in his her own neighbourhood,

(b) riding in public transportation (train, bus, tram),

(c) walking home from the train/tram/bus stop.

Wherever relevant, respondents were excluded from the analysis if, for reasons unrelated to fear of crime, they were never likely to be in the situation in question (e.g. if they said they never went out, or never used public transport); on the other hand, respondents were considered as fearful if they avoided those situations out of fear of crime. In order to be able to consider this group as fearful without questionable interpretations, all items on fear were dichotomized. ${ }^{8}$

Independent of their own feelings of safety, respondents were asked how safe they viewed elderly people and young women in their own (i.e. the respondent's) neighbourhoods. A further question concerned safety measures taken while going out, i.e. whether or not the respondent usually avoided certain streets, places or people while walking after 10 p.m. in his/her neighbourhood. Finally, respondents were asked how

\footnotetext{
${ }^{4}$ Given the small size of the Italian-speaking parts of Switzerland (5 per cent of the national population), it is standard practice to exclude these regions in surveys with less than 5,000 respondents.

${ }^{5}$ Since this was not always the case, it was decided to ask the respondent about the characteristics of his area of residence, rather than to use interviewer ratings.

${ }^{6}$ The full questionnaire (in French or German) with frequencies can be obtained from the authors.

${ }^{7}$ Response categories were: (1) very safe, (2) fairly safe, (3) fairly unsafe, (4) very unsafe, (5) never go out because of fear of crime, (6) never go out for reasons unrelated to fear of crime, (7) don't know, (8) no answer.

${ }^{8}$ Thus, those answering feeling very or rather unsafe, or never to be in the situation in question out of fear of crime, were considered as fearful; those who said feeling very or rather safe, were considered as not fearful.
} 
they rated the likelihood of their house or apartment being broken into during the next 12 months.

Concerns for personal safety turned out to be about as prevalent as in former crime surveys of this kind (Schwarzenegger 1991; Killias 1989).${ }^{9}$ Roughly between one fifth and one fourth admitted feeling very or somewhat unsafe, and 30 per cent said they avoided places or people, while walking at night in their own neighbourhood and certain streets, The most prevalent was, interestingly, the expectation of burglary within the next 12 months (36 per cent).

\section{Measures of vulnerability}

As in the Swiss survey of 1987, respondents were asked how they assessed their chances in the event of an assault on a lonely street by a young, unarmed man, i.e. whether they felt able to flee or to defend themselves, or whether they expected to succumb under such circumstances. ${ }^{10}$ In the present research, however, advantage was taken of the fact that personal interviews allowed direct contact between the interviewer and the respondent. Therefore, certain aspects of vulnerability could be assessed through visual ratings, rather than merely through verbal questioning. Therefore, interviewers were asked to rate silently a certain number of physical characteristics of the respondent, such as

(a) his weight, ${ }^{11}$

(b) the presence of physical handicap, ${ }^{12}$

(c) the respondent's physical shape (health condition) in general, ${ }^{13}$

(d) his/her self-confidence, ${ }^{14}$

(e) his/her likely vulnerability in case of a (hypothetical) attack, i.e. whether he/she might be an 'easy' victim from, for example, a mugger's viewpoint. ${ }^{15}$

In addition, respondents were asked about characteristics of their place of residence, and composition of their household. In this connection, they were asked whether or not graffiti was common on the walls in their neighbourhood, whether garbage was left on the streets, or whether people they might view as 'strange' hung around there. Another question concerned the proximity of a forest, a park, or a wasteground near their house or apartment.

\footnotetext{
${ }^{9}$ For details, see the raw data which can be obtained from the authors.

${ }^{10}$ The response categories were: (1) I'm sure I'd be able to escape or to defend myself, (2) I'd probably be able to escape or to defend myself, (3) it depends, (4) I'd probably give in, (5) I'm sure I'd give in, (6) don't know, (7) no answer. For the following analyses, the categories (1) and (2), on one hand, and (4) and (5), on the other hand, were combined. Respondents falling in the remaining categories were excluded.

${ }^{11}$ The wording was: How would you rate the respondent's weight? (1) clearly under the norm, (2) rather under the norm, (3) normal, (4) rather over the norm, (5) clearly over the norm, (6) don't know.

${ }^{12}$ Does the respondent suffer from any visible handicap? (1) no, (2) yes, he/she walks with difficulty (limping), (3) yes, he/she uses a stick or walks on crutches, (4) yes, he/she uses a wheelchair, (5) yes, he/she suffers from heart or breathing problems (e.g. asthma), (6) yes, he/she suffers from blindness or problems with visual orientation, (7) yes, he/she is hard of hearing, (8) other (specify), (9) don't know.

${ }^{13}$ How would you rate the respondent's physical shape, given his/her age? (1) healthy, fit, (2) about average, (3) unhealthy, not fit, (4) don't know.

${ }^{14}$ Does the respondent give you the impression of being self-confident? (Yes/fairly/not really/no/don't know)

${ }^{15}$ Would you say the respondent might be an 'easy' victim from the point of view of an eventual assailant, such as, for example, a mugger? (Yes/probably/probably not/no/don't know).
} 


\section{Interviewer effects on responses and ratings ${ }^{16}$}

In order to identify possible interviewer effects, all answers given by respondents in relation to fear of crime, as well as all interviewer ratings, were correlated with sex and age of both the interviewer ${ }^{17}$ and the respondent.

It turned out that interviewer's age, if simultaneously controlled for gender, is significantly $(\mathrm{p}<.05)^{18}$ associated with only one measure of fear of crime, i.e. perceived problems in neighbourhood streets (litter, vandalism, 'strange' people; gamma =.263); those interviewed by younger interviewers were more reluctant to admit or perceive neighbourhood problems. The interviewer's gender was, after control for age, significantly associated with perceived burglary risks (if the interviewer was older than 40, gamma $=.456$ ), perceived problems in neighbourhood streets (if the interviewer was younger than 40 , gamma $=.350$ ) and perceived vicinity of 'dark' areas (parks, forests, waste areas etc.; if the interviewer was older than 40 , gamma $=.370$ ). In these cases, respondents were less inclined to admit perceived neighbourhood problems in front of a female interviewer; on the other hand, respondents were more ready to say burglary was likely over the next year if the interviewer was female.

All other items on perceived risks and fear, including fear in the streets after 10 p.m., avoiding certain areas after 10 p.m., and worry for third parties (elderly persons and young women), were not significantly related to interviewer's age and gender. It may be that admitting certain concerns, such as 'strange' people hanging around in one's neighbourhood, is considered as 'undesirable' and will, therefore, be concealed in front of an interviewer who, according to certain criteria, might be perceived as less sympathetic to such attitudes. Other items, however, may be more related to factual information, such as avoiding certain streets, and will consequently be admitted independently of interviewer characteristics.

As far as interviewer ratings of respondent characteristics (e.g. his/her vulnerability) are concerned, a moderate effect of the female interviewer's age could be found in connection with assessments of the respondent's physical condition (gamma =.262) and vulnerability ('easy' victim, gamma $=.196$ ); here, older interviewers tended to see the respondent more optimistically. The interviewer's gender had an impact only on assessments of physical handicap of the respondent, in the sense that male interviewers were more often inclined to note them. In other words, more 'vulnerable' (i.e. female and older) interviewers had a slight tendency to rate the respondent as less vulnerable. It should be noted, however, that all the other respondent characteristics were unaffected by the interviewer's sex and age. Even more important, in view of the following analyses, is the finding that the respondent's self-assessed vulnerability (in case of a hypothetical attack) is in no case significantly associated with the interviewer's sex and age.

In the case of vulnerability (i.e. being an 'easy' victim), special attention has been given to characteristics of interviewers and respondents in those cases where self-assessments of vulnerability by the respondent did not match with interviewer ratings. Such disagreement

\footnotetext{
16 The detailed results for this part of the paper can be obtained from the authors on request.

17 Forty per cent of the interviews were conducted by a person younger than 40,46 per cent by an interviewer aged between 40 and 64 , and 7 per cent by a person aged 65 or older. Younger respondents (below 39 ) tended to be slightly more often interviewed by men than on average (41, as against 37 per cent).

18 The Mantel-Haenszel-Test for linear association was used in these analyses.
} 
was more frequent (52 per cent) when the interviewer rated the respondent as vulnerable than when the respondent did so himself or herself (36 per cent). It concerned predominantly respondents below 65 who were rated as vulnerable, but who still saw themselves as capable of escaping or fighting back in the case of an attack, whereas older respondents saw themselves rather as more vulnerable than the interviewer did. In other words, one's own sense of vulnerability tends to increase more slowly with age than the judgement of an observer, especially before the age of 65 . The kind of disagreement was unrelated to the respondent's gender. However, an important finding is that the frequency or the direction of disagreements is in no way related to the interviewer's age or gender.

Overall, these findings are in line with a long experience in survey research that interviewer effects, i.e. biases in favour of socially desirable responses, may be more problematic in connection with items related to attitudes, than in the domain of factual information. For future research on fear of crime and vulnerability, it would be advisable to consider moderate interviewer effects in relation to measures of fear which are somehow related to attitudes towards deviants and deviance, whereas measures of vulnerability may be less problematic.

\section{Results}

\section{Correlations between different measures of fear}

Certain measures of fear of crime are highly correlated, whereas others are at best moderately correlated (Table 1 ).

The simple correlations suggest that 'fear of crime' is highly dependent on situational circumstances. Fear while walking alone at night in the neighbourhood is, plausibly, almost perfectly correlated (.98) with fear while walking home at night from the train, bus or tramway stop, and fear while riding in public transportation (.90). Concern for the safety of elderly people or young women is only moderately correlated with measures of personal fear, suggesting that respondents assess their own risk quite independently of others. Precautions taken while going out, such as avoiding certain streets, are more highly correlated with measures of personal fear than with worries about crime risks for

TABLE 1 Simple correlations (gamma) between different measures of fear of crime.

\begin{tabular}{|c|c|c|c|c|c|c|c|c|c|c|}
\hline & \multicolumn{2}{|c|}{ Street } & \multicolumn{2}{|c|}{$\begin{array}{l}\text { Public } \\
\text { transport }\end{array}$} & \multicolumn{2}{|c|}{ Way home } & \multicolumn{2}{|c|}{ Precautions } & \multicolumn{2}{|c|}{$\begin{array}{c}\text { Elderly and } \\
\text { women }\end{array}$} \\
\hline & $\gamma$ & $\mathrm{N}$ & $\gamma$ & $\mathrm{N}$ & $\gamma$ & $\mathrm{N}$ & $\gamma$ & $\mathrm{N}$ & $\gamma$ & $\mathrm{N}$ \\
\hline Public transport & .90 & 631 & & & & & & & & \\
\hline Way home & .98 & 640 & .94 & 624 & & & & & & \\
\hline Precautions & .81 & 676 & .66 & 611 & .71 & 620 & & & & \\
\hline Elderly and women & .67 & 686 & .63 & 616 & .56 & 627 & .33 & 660 & & \\
\hline Expected burglary & .24 & 652 & .27 & 591 & $.18^{\mathrm{a}}$ & 602 & $.15^{\mathrm{a}}$ & 651 & .33 & 630 \\
\hline
\end{tabular}

a $\mathrm{p}<.05$.

$\mathrm{p}$ is always $<.01$, except where indicated. 
the elderly and women, or about burglary. Finally, burglary risks for the home are assessed independently of measures of personal fear in the streets. Thus, fear of crime and worries seem to depend on situational circumstances, as others have suggested (Fisher and Nasar 1995; Hale et al. 1994; Nair et al. 1993), rather than on personal characteristics alone. Given the highly variable size of the correlations, it seems preferable ${ }^{19}$ to analyse the several dimensions of fear and worries separately, rather than to combine them in a single index. The multivariate analyses have indeed shown that models based on one single dimension do better than those based on an index of fear and worries about crime.

\section{Correlations between different measures of physical vulnerability}

Given the absence of research on the validity of various measures of physical vulnerability in relation to fear of crime, several-admittedly subjective-interviewer ratings of physical characteristics were used to corroborate respondents' self-assessed vulnerability (Table 2).

The simple correlations given in Table 2 suggest that physical vulnerability is a complex concept, with likely interactions of social, bodily and psychological aspects. The correlation between interviewers' and respondents' assessments of vulnerability (i.e. inability to escape or defend) is very high (.83) in case of an assault. Thus, the 'easy victim' concept seems to have some 'real' meaning. Being an 'easy' victim is, however, not merely a matter of certain physical traits or shape, such as an abnormally high or low body weight, suffering from a visible handicap, or a lack of self-confidence, although, as the correlations indicate, such aspects are of some importance. However, being an 'easy' victim, as assessed by the interviewer, is most strongly related to self-admitted vulnerability during the interview. This verbal measure of vulnerability also has the practical advantage of being available in the case of interviews without direct face to face contact between the respondent and the interviewer.

TABLE 2 Simple correlations (gamma) between different measures of physical vulnerability ${ }^{\mathrm{a}}$

\begin{tabular}{|c|c|c|c|c|c|c|c|c|c|c|}
\hline & \multicolumn{2}{|c|}{$\begin{array}{l}\text { Self-assessed } \\
\text { vulnerability }\end{array}$} & \multicolumn{2}{|c|}{$\begin{array}{l}\text { Interv. ass. } \\
\text { vulnerability }\end{array}$} & \multicolumn{2}{|c|}{$\begin{array}{c}\text { Self- } \\
\text { confidence }\end{array}$} & \multicolumn{2}{|c|}{$\begin{array}{l}\text { Physical } \\
\text { shape }\end{array}$} & \multicolumn{2}{|c|}{ Handicaps } \\
\hline & $\gamma$ & $\mathrm{N}$ & $\gamma$ & $\mathrm{N}$ & $\gamma$ & $\mathrm{N}$ & $\gamma$ & $\mathrm{N}$ & $\gamma$ & $\mathrm{N}$ \\
\hline $\begin{array}{l}\text { Interviewer-ass. } \\
\text { vulnerability }\end{array}$ & .83 & 488 & & & & & & & & \\
\hline Self-confidence & .61 & 497 & .86 & 704 & & & & & & \\
\hline Physical shape & .70 & 491 & .82 & 702 & .76 & 715 & & & & \\
\hline Handicaps & .61 & 490 & .67 & 695 & .56 & 713 & .84 & 706 & & \\
\hline Weight & .41 & 492 & .35 & 702 & .47 & 715 & .21 & 714 & $.72(p>.05)$ & 706 \\
\hline
\end{tabular}

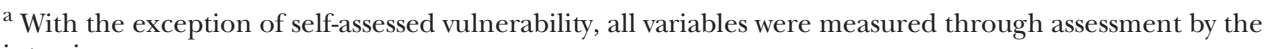
interviewer.

$\mathrm{p}$ is always $<.01$, except where indicated.

\footnotetext{
${ }^{19}$ It also makes interpretation of findings and models less questionable.
} 


\section{KILLIAS AND CLERICI}

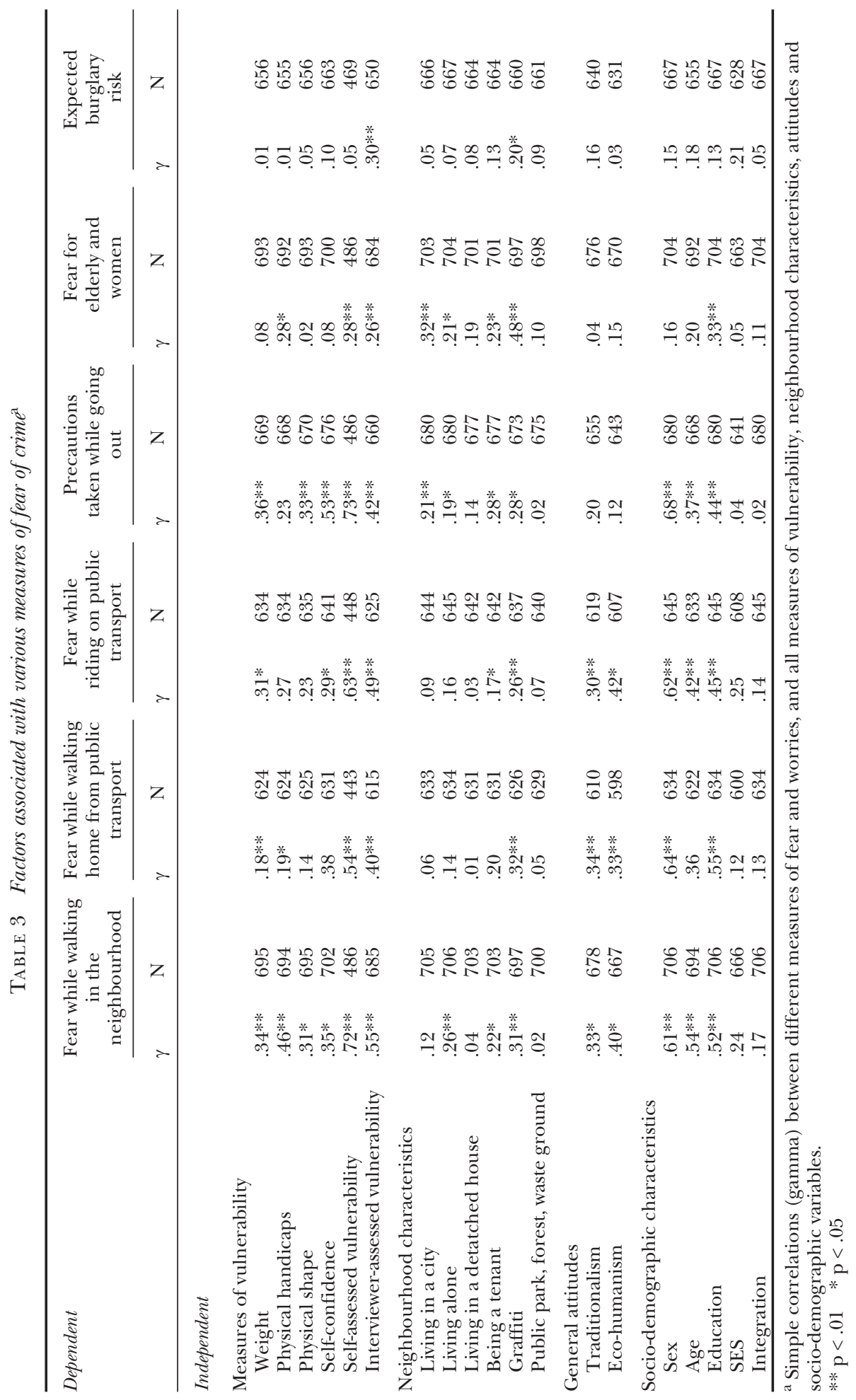




\section{Correlations (gamma) between fear and independent variables}

Before looking at multivariate relations, all measures of fear used here have been correlated with all relevant independent variables. The correlations were higher if the several measures of vulnerability were kept separate, rather than being combined in an index. Like the other variables, they were dichotomized in order to reduce the problems of extreme distributions across cells; thus, persons who are somewhat or very fearful, or who see themselves as somewhat or certainly inferior to a potential (hypothetical) young assailant, were merged into categories of 'fearful', or 'vulnerable'. This procedure allowed the inclusion of all those who said they would not go out because of fear of crime in the category of 'fearful' respondents without questionable interpretations.

The results confirm that the several forms of personal fear of crime, as well as precautions taken while going out, are correlated with more or less the same independent variables, whereas assessing burglary risks and worries for hypothetical third parties (elderly people and young women) showed a different pattern. We shall look at these differences more closely in the following sections.

As Table 3 shows, the subjective (verbal) measure of vulnerability is more strongly correlated with all measures of personal fear of crime than its interviewer-assessed counterpart. Since fear of crime, as measured here, is a subjective assessment of one's feelings of safety, it seems indeed plausible that it is more strongly correlated with an equally subjective measure of vulnerability. As will be shown below, these first impressions, based on simple correlations, were corroborated during the multivariate analyses.

\section{Multivariate models}

On the basis of the independent variables used in Table 3, several models were developed and tested, through logistic regressions, in the search of explanations of fears and worries provoked by crime. The best performing models are summarized in Table $4 .{ }^{20} \mathrm{~A}$ separate model was computed for each dependent variable, rather than combining several dependent variables into an index (see above). In the table the logistic regression models explain four dimensions of personal fear of crime, worries about safety for the elderly or women, and burglary risk. ${ }^{21}$

The first four models (Table 4a-4d) concern several dimensions of personal fears. Given the high correlations (ranging from .66 to .98) between fear, after 10 p.m., while walking in the neighbourhood, or walking home from public transport stops, while riding on a train and precautions taken while going out, it comes as no surprise that similar models tend to do best in explaining these forms of fear. Being female and seeing oneself as vulnerable are the only variables that contribute significantly and consistently in explaining all four dimensions of personal fear. If regression coefficients $(\mathrm{R})$ are considered, gender comes first in three of the four models. Vulnerability ranks first in model $4 \mathrm{a}$, second in models $4 \mathrm{~b}$ and $4 \mathrm{~d}$, and fourth in model 4c. Age, however, is significant only in two of the four models of personal fear, and never makes it beyond the third rank. It was, in the multivariate models, not significantly related to fear while using public transport.

${ }_{20}$ All possible interactions were included as well, but turned out to be non significant (with one exception in Table 4c).

${ }^{21}$ Note that the number of missing observations (and, thus, the size of $\mathrm{N}$ ) differs between the several models. 


\section{KILLIAS AND CLERICI}

TABLE 4 Logistic regression models explaining four dimensions of personal fear of crime, and worries about the elderly's or women's safety, and burglary risk. ${ }^{\text {a }}$

TABLE 4a Fear while walking in the neighbourhood after 10 p.m. $(N=453)$

\begin{tabular}{lll}
\hline Variables & $\mathrm{R}$ & $\mathrm{Exp}(\mathrm{B})$ \\
\hline Sex & $.1722^{* *}$ & 3.23 \\
Age & $.1407 * *$ & 3.22 \\
Vulnerability (self-assessed) & $.1752^{* *}$ & 3.21 \\
Being a tenant & $.1173^{* *}$ & 3.16 \\
Living in a detached house & $.0847^{*}$ & 2.44 \\
Neighbourhood (run down) & $.0861^{*}$ & 1.91 \\
Traditionalist attitudes & .0139 & 1.75 \\
\hline
\end{tabular}

a Note that the number of missing observations (and thus the size of $\mathrm{N}$ ) differs between the several models.

Percentage correctly classified: fearful 34, overall 80. ** $\mathrm{p}<.01 * \mathrm{p}<.05$.

TABLE 4b Fear while going home from the bus stop of public transport $(N=418)$

\begin{tabular}{lll}
\hline Variables & $\mathrm{R}$ & $\mathrm{Exp}(\mathrm{B})$ \\
\hline Sex & $.1954^{* *}$ & 3.40 \\
Age & $.1184^{* *}$ & 2.77 \\
Being a tenant & $.0954^{* *}$ & 2.54 \\
Living in a detached house & $.0961^{* *}$ & 2.53 \\
Vulnerability (self-assessed) & $.1327^{* *}$ & 2.40 \\
Traditionalist attitudes & $.0839^{*}$ & 2.33 \\
Neighbourhood (run down) & $.0818^{*}$ & 1.83 \\
\hline
\end{tabular}

Percentage correctly classified: fearful 32, overall 75. $* * \mathrm{p}<.01 \quad * \mathrm{p}<.05$.

TABLE 4c Fear while riding on public transport (train, bus, tramway) $(N=429)$

\begin{tabular}{lll}
\hline Variables & $\mathrm{R}$ & $\mathrm{Exp}(\mathrm{B})$ \\
\hline Sex & $.2285^{* *}$ & 4.28 \\
Living alone & $.1350^{* *}$ & 3.05 \\
Education (low) & $.1329^{* *}$ & 2.83 \\
Neighbourhood (run down) & $.1264^{* *}$ & 2.59 \\
Vulnerability (self-assessed) & $.0760^{*}$ & 1.83 \\
Age & .0000 & 1.31 \\
Neighbourhood $\times$ household composition & $-.0683^{*}$ & 0.29 \\
$\quad$ (interaction) & & \\
\hline
\end{tabular}

Percentage correctly classified: fearful 36, overall 77. $* * \mathrm{p}<.01 * \mathrm{p}<.05$.

TABLE 4d Precautions taken while going out after 10 p.m. $(N=452)$

\begin{tabular}{lll}
\hline Variables & $\mathrm{R}$ & $\mathrm{Exp}(\mathrm{B})$ \\
\hline Sex & $.2650^{* *}$ & 5.11 \\
Vulnerability (self-assessed) & $.1945^{* *}$ & 3.64 \\
Age & .0535 & 2.01 \\
Being a tenant & $.0707^{*}$ & 1.78 \\
Living in city & $.0680^{*}$ & 1.72 \\
Neighbourhood (run down) & $.0630^{*}$ & 1.69 \\
\hline
\end{tabular}

Percentage correctly classified: 69 of those who take precautions, overall 76 .

$* * \mathrm{p}<.01 * \mathrm{p}<.05$ 
DIFFERENT MEASURES OF VULNERABILITY

TABLE 4e Fear for elderly people and young women in the neighbourhood $(N=696)$

\begin{tabular}{lll}
\hline Variables & $\mathrm{R}$ & $\mathrm{Exp}(\mathrm{B})$ \\
\hline Neighbourhood (run down) & $.1724^{* *}$ & 2.65 \\
Education (low) & $.0911^{* *}$ & 1.99 \\
Living in city & $.0686^{*}$ & 1.63 \\
Living alone & $.0590^{*}$ & 1.59 \\
\hline
\end{tabular}

Percentage correctly classified: fearful 8, overall 77. ** $\mathrm{p}<.01 \quad * \mathrm{p}<.05$.

TABLE 4f Perceived burglary risk for the next 12 months $(N=541)$

\begin{tabular}{lll}
\hline Variables & $\mathrm{R}$ & $\mathrm{Exp}(\mathrm{B})$ \\
\hline Interviewer's gender & $.1431^{* *}$ & 2.20 \\
Vulnerability (assessed by interviewer) & $.1136^{* *}$ & 1.98 \\
Neighbourhood (run down) & $.0978^{* *}$ & 1.89 \\
Traditionalist attitudes & .0266 & 1.49 \\
Sex & .0000 & 1.13 \\
Age & .0000 & 0.67 \\
\hline
\end{tabular}

Percentage correctly classified: fearful 34, overall 65. ** $\mathrm{p}<.01 * * \mathrm{p}<.05$.

Being a tenant ${ }^{22}$ and living in a detached house ${ }^{23}$ are significantly related to three and two models respectively of personal fear. Living in a city (instead of in a rural or suburban area) plays a role only in connection with precautions, and even then not very convincingly. This may reflect the diminishing differences between living in Switzerland's relatively small towns, and in the remaining (usually suburban) areas. More important is the visible presence of signs of decay in the neighbourhood, such as litter, graffiti and 'strange' people hanging around (Lewis and Maxfield 1980); it appears in all six models and so contributes to the explanation of personal fears as well as of worries, although $\mathrm{R}$ scores and odds ratios tend to be modest in most models. Other variables tend to appear only in single models, such as (low) education, ${ }^{24}$ holding traditionalist values ${ }^{25}$ and household composition (i.e. living alone) ${ }^{26}$

Given the interest of interviewer effects for future research, we tried to take the interviewer's age and gender of all models into account. These additional variables were significant in none of the models considered, with the exception in explaining perceived burglary risks (Table 4f). Taking the interviewer's gender into account, however, increased the percentage of individuals who were correctly classified as 'fearful'. ${ }^{27}$

Of interest also are the differences in correct classifications among the six models. The four models explaining personal fears classify as predicted between 74 and 80 per cent of

\footnotetext{
${ }^{22}$ Which probably means living in a less privileged area.

${ }^{23}$ With probably more 'dark' spots in the neighbourhood, cf. Fisher and Nasar (1995).

${ }^{24}$ Significant only in models $4 \mathrm{c}$ and $4 \mathrm{e}$.

${ }^{25}$ Significant only in model $4 \mathrm{~b}$.

${ }^{26}$ Significant only in model 4e. Living alone can be seen as a special aspect of vulnerability, in so far as people who have nobody to take care of them in case of an emergency are indeed more vulnerable (cf. Roché 1993).

${ }^{27}$ For example, in model 4a the percentage correctly classified as 'fearful' increased (from 34) to 38, in model $4 \mathrm{~b}$ from 32 to 41 per cent, in model $4 \mathrm{e}$ from 8 to 14 per cent. The overall proportion of correctly classified respondents never increased by more than 2 per cent.
} 
the respondents overall, and between 32 and 69 per cent of those who were predicted as 'fearful'. The two models explaining worries (4e and $4 \mathrm{f}$ ) turn out to be much less powerful. This means that the variables considered here are more related to fears than to worries, and that different variables may be needed to explain perceived burglary risks and worries about the safety of the elderly or young women.

Perhaps even more important is the failure of all interviewer-assessed measures of vulnerability to contribute, to the same extent as self-assessed vulnerability, to personal fear of crime. With one exception, they even fail to contribute to worries about crime. Therefore, asking respondents directly about their self-perceived ability to defend themselves or to escape in the case of a (hypothetical) attack by a young robber, is not only possible in the case of telephone or mail surveys, but may even lead to more valid measures of vulnerability. As we have noted above, it happens more often that the interviewer sees the respondent as vulnerable, whereas the latter does not, than that they disagree the other way round. Particularly younger respondents are sometimes less critical than an observer. It has to remain open whose judgement is more realistic. However, it is feasible that a respondent's denial of vulnerability may be associated with more optimistic views about his personal safety. In this sense, it is plausible that personal fear of crime, being equally subjective and self-perceived, may best be explained by how respondents themselves think they are able to cope with potential threats.

\section{Discussion}

The results have shown that fear of crime in the streets and at night has very little to do with ideological or political orientation, education, SES or other socio-demographic variables. It increases mostly with sex, physical vulnerability and age, and with neighbourhood characteristics which are correlated with objective risks, such as graffiti, people hanging around, or litter in the streets. Thus, fear of personal crime and burglary is widely explained by variables which are somehow related either to objective risks, or to the likely seriousness of the consequences, or to the inability of the respondent to control risks or outcome, or both.

The observed differences between the fear while walking in the streets model and while using public transportation are plausible. Since risk of direct physical confrontation may not be in the foreground while riding on a train, it makes sense that these fears are less dependent on age and vulnerability. However, gender remains important since 'assaults' in public transport usually take the form of harassment, to which women are particularly exposed and which largely shape their feelings of fear (Pain 1995; Walklate 1997). It also makes sense that the characteristics of the neighbourhood where the bus, train or tramway is running plays a significant role, since the likelihood of having uncomfortable encounters with other passengers clearly varies by geographic area.

Perceived burglary risk and worries for the safety of the elderly and of women in one's own neighbourhood tend to depend on neighbourhood characteristics (signs of decay, Lewis and Maxfield 1980) rather than on demographic factors and on personal vulnerability. This seems to suggest that respondents distinguish between threats to their personal safety, to the safety of others, and to their apartment. The only inconsistency are worries about burglary which seems to increase with vulnerability (i.e. being an 'easy' victim), as assessed by the interviewer, but not with other measures of vulnerability and not even 
with age. Worries for (vulnerable) others, including burglary, are, however, significantly related to neighbourhood characteristics (graffiti, litter, 'strange' people hanging around). Concern for others, as well as expected burglary risk, may be related to a perceived lack of social control in the area in question, i.e. they may increase with objective risks which are likely to be correlated with such neighbourhood characteristics (Hale et al. 1994).

A final interesting result is the absence of significant contributions to the models by the remaining variables, such as SES, social integration, and attitudes. ${ }^{28}$ Given the great attention to variables such as unemployment, social decay, and political or religious attitudes in theoretical explanations of fear of crime (Robert and Pottier 1997), the results observed here may necessitate revising some popular beliefs among scholars and policy makers. Much more than being related to such factors, fear of crime in the public sphere, i.e. in the streets or in public transportation, seems to be a matter of sex, vulnerability and neighbourhood characteristics.

\section{Conclusions}

Even when competing with several other independent variables, and even in relation to various measures of fear, vulnerability turned out to be a very important factor in the explanation of personal feelings of fear of crime. Sex, but not age, remains important, even after control for vulnerability (i.e. inability to cope with a physical attack). This may reflect women's special exposure to sexual assault and harassment (Pain 1995). Neighbourhood characteristics, i.e. signs of decay (graffiti, litter, 'strange' people hanging around) are important, but less so than personal vulnerability. Worries about burglary risk and the safety of vulnerable people (i.e. the elderly and women) are probably related to factors beyond the respondent's personal characteristics.

Situational factors, related to 'hotspots' eliciting fear (Fisher and Nasar 1995), street lighting and environmental improvements (Nair and Ditton 1995), have not been included here, with the exception of perceived signs of decay in the neighbourhood. The issue of situational dimensions (Obergfell-Fuchs and Kury 1996) of vulnerability should, therefore, not be considered closed. However, future surveys should try to include a verbal question on perceived (in)ability to escape or defend oneself against a possible young assailant. It could be shown that such a question might do better than observed measures of vulnerability in explaining personal fears of crime.

\section{References}

Alimam, A. (1993), Le Sentiment d'Insécurité: Etude Théorique et Conceptuelle. Lausanne: Institut de Police Scientifique et de Criminologie de l’Université de Lausanne.

Bandura, A. (1986), 'Fearful Expectations and Avoidant Actions as Coeffects of Perceived SelfInefficacy', American Psychologist, 41: 1389-91.

Fisher, B. and Nasar, J. L. (1992), 'Design for Vulnerability: Clues and Reactions to Fear of Crime', Sociology and Social Research, 76: 48-56.

\footnotetext{
${ }^{28}$ With one exception in model $4 \mathrm{~b}$.
} 


\section{KILLIAS AND CLERICI}

(1995), 'Fear Spots in Relation to Microlevel Physical Clues: Exploring the Overlooked', Journal of Research in Crime and Delinquency, 32: 214-39.

Goffman, E. (1973), La Mise en Scène de la Vie Quotidienne: Les Relations avec le Public. Paris: Les Editions de Minuit.

Greve, W., Hosser, D. and Wetzels, P. (1996), Bedrohung durch Kriminalität im Alter. BadenBaden: Nomos Verlafsgesellschaft.

Hale, C. (1996), 'Fear of Crime: A Review of the Literature', International Review of Victimology, 4: $79-150$.

Hale, C., Pack, P. and SAlked, J. (1994), 'The Structural Determinants of Fear of Crime: An Analysis Using Census and Crime Survey Data from England and Wales', International Review of Victimology, 3: 211-33.

Hough, M. (1995), 'Anxiety about Crime: Findings from the 1994 British Crime Survey', Research Findings, 25: 1-4.

- (1996), 'Anxiety about Crime': Findings from the 1994 British Crime Survey. London: Home Office.

Killias, M. (1989), Les Suisses Face au Crime. Grüsch: Verlag Rüegger.

— (1990), 'Vulnerability: Towards a Better Understanding of a Key Variable in the Genesis of Fear of Crime', Violence and Victims, 5: 97-108. (1991), Précis de criminologie. Berne: Stämpfli.

Lewis, D. A. and Maxfield, M. G. (1980), 'Fear in the Neighbourhoods: an Investigation of the Impact of Crime', Journal of Research and Delinquency, 17: 160-89.

Mirrlees-Black, C. and Allen, J. (1998), 'Concern about Crime. Findings from the 1998 British Crime Survey', Research Findings, 83.

Nair, G. and Ditton, J. (1995), 'Throwing Light on Crime: a Case Study of the Relationship between Street Lighting and Crime Prevention', Security Journal, 5: 125-32.

Nair, G., Ditton, J. and Phillips, S. (1993), 'Environmental Improvements and the Fear of Crime. The Sad Case of the "Pond" Area in Glasgow', British Journal of Criminology, 33: 555-61.

Obergfell-Fuchs, J. and Kury, H. (1996), 'Sicherheitsgefühl und Persönlichkeit', Monatsschrift für Kriminologie und Strafrechtsreform, 79: 97-113.

PaIn, R. H. (1995), 'Elderly Women and Fear of Violent Crime: The Least Likely Victims? A Reconsideration of the Extent and Nature of Risk', British Journal of Criminology, 35: 584-97.

Robert, P. and Pottier, M.-L. (1997), 'On ne se sent plus en sécurité: délinquance et insécurité, une enquête sur deux décennies', Revue Française de Science Politique, 47: 707-40.

Roché, S. (1993), Le Sentiment d'Insécurité. Paris: Presses Universitaires de France.

Schwarzenegger, C. (1991), 'Public Attitudes to Crime: Findings of the Zürich Victim Survey', in G. Kaiser, H. Kury and H.-K. Albrecht, Victims and Criminal Justice, 1. Freiburg: Max-PlanckInstitut für Ausländisches und Internationalisches Strafrecht.

Skogan, W. G. and Maxfield, G. M. (1981), Coping with Crime: Individual and Neighbourhood Reactions. London: Sage.

VRiJ, A. and Winkel, F. W. (1991), 'Characteristics of the Built Environment and Fear of Crime: a Research Note on Interventions in Unsafe Locations', Deviant Behaviour, 12: 203-15.

Walklate, S. (1997), 'Risk and Criminal Victimization-A Modernist Dilemma?', British Journal of Criminology, 37: 35-45. 